\title{
How to manage intravenous
} vinflunine in cancer patients with renal impairment:

\section{results of a pharmacokinetic and tolerability phase I study}

Nicolas Isambert, ${ }^{1}$ Jean Pierre Delord, ${ }^{2}$ Jean Marc Tourani, ${ }^{3}$ Pierre Fumoleau, ${ }^{1}$ Alain Ravaud, ${ }^{4}$ Marie Claire Pinel, ${ }^{5}$ Aurelie Petain, ${ }^{5}$ Thierry Nguyen ${ }^{6} \&$ Laurent Nguyen ${ }^{5}$

${ }^{1}$ Medical Oncology, Centre G.F. Leclerc, Dijon, ${ }^{2}$ Institut Claudius Regaud, Toulouse, ${ }^{3}$ Chu de Poitiers, Poitiers, ${ }^{4}$ Hopital Saint Andre, Bordeaux, ${ }^{5}$ Institut de Recherche Pierre Fabre, Pharmacokinetic Oncology Department, Toulouse and ${ }^{6} \mathrm{Chu}$ Jean Minjoz, Besançon, France

\section{WHAT IS ALREADY KNOWN ABOUT}

\section{THIS SUBJECT}

- Vinflunine, a novel tubulin-targeted inhibitor, is indicated as a single agent for the treatment of bladder cancers after failure of prior platinum-based therapy. - In cancer patients, vinflunine is predominantly metabolized by both CYP3A4 and multiple esterases and about one third of a total radiolabelled dose is recovered in urine.

\section{WHAT THIS STUDY ADDS}

- The pharmacokinetics and tolerability of vinflunine were evaluated in patients with renal impairment.

-A $12 \%$ and $22 \%$ dose reduction, respectively, are needed in patients with moderate (creatinine clearance $\left(\mathrm{CL}_{\mathrm{cr}}\right)$ between 40 and $60 \mathrm{ml} \mathrm{min}^{-1}$ ) and severe renal impairment $\left(\mathrm{CL}_{c r}\right.$ between 20 and $<40 \mathrm{ml} \mathrm{min}{ }^{-1}$ ). A $50 \%$ dose reduction is suggested in patients with end stage renal disease undergoing dialysis.

\section{AIMS}

Vinflunine (VFL) ditartrate, a novel tubulin-targeted inhibitor, is registered for the treatment of patients with advanced or metastatic urothelial transitional cell carcinoma. This phase I study assessed the effect of renal impairment on the pharmacokinetics and tolerability of VFL.

\section{METHODS}

VFL was infused in patients with advanced/metastatic solid tumours once every 3 weeks with anticipated dose reduction on the first cycle stratified according to the creatinine clearance $\left(\mathrm{CL}_{\mathrm{cr}}\right)$ values. Pharmacokinetic data were collected on the first two cycles in renally impaired patients $\left(\mathrm{CL}_{\mathrm{cr}} \leq 60 \mathrm{ml} \mathrm{min}^{-1}\right)$ and were compared with a control cohort of patients $\left(\mathrm{CL}_{\mathrm{cr}}>60 \mathrm{ml} \mathrm{min}^{-1}\right)$.

\section{RESULTS}

Thirty-three patients (46-86 years) were treated, 13 in group $1\left(40 \mathrm{ml} \mathrm{min}^{-1} \leq\right.$ $\left.\mathrm{CL}_{\mathrm{cr}} \leq 60 \mathrm{ml} \mathrm{min}^{-1}\right)$ and 20 in group $2\left(20 \mathrm{ml} \mathrm{min}^{-1} \leq \mathrm{CL}_{\mathrm{cr}}<40 \mathrm{ml} \mathrm{min}^{-1}\right)$. The renal dysfunction induced a mean decrease in VFL clearance of $12 \%$ in group 1 and $28 \%$ in group 2 , compared with the control group. The anticipated dose reduction given in renally impaired patients (i.e. $280 \mathrm{mg} \mathrm{m}^{-2}$ and $250 \mathrm{mg} \mathrm{m}^{-2}$ in groups 1 and 2, respectively) yielded similar drug exposure to control patients. The tolerance profile of VFL in patients with renal dysfunction was similar to that observed in patients with $\mathrm{CL}_{\mathrm{cr}}>60 \mathrm{ml} \mathrm{min}{ }^{-1}$.

\section{CONCLUSION}

In conclusion, the recommended doses of intravenous VFL administered once every 3 weeks in cancer patients with renal impairment are $280 \mathrm{mg} \mathrm{m}^{-2}$ when $\mathrm{CL}_{c r}$ is between 40 and $60 \mathrm{ml} \mathrm{min}^{-1}$ and $250 \mathrm{mg} \mathrm{m}^{-2}$ when $\mathrm{CL}_{\mathrm{cr}}$ is between 20 and $<40 \mathrm{ml} \mathrm{min}{ }^{-1}$. 


\section{Introduction}

Vinflunine (VFL) ditartrate, is a novel tubulin-targeted inhibitor belonging to the vinca alkaloid family. This bifluorinated semi-synthetic molecule was selected for its particular mechanism of action and its higher level on in vivo anti-tumour activity compared with vinblastine or vinorelbine [1-4]. The intravenous (i.v.) formulation of VFL (Javlor ${ }^{\circ}$, Pierre Fabre Médicament) received a European marketing authorization as a single agent for the treatment of adult patients with advanced transitional cell carcinoma of the urothelium (TCCU, bladder cancer) after failure of a prior platinum-containing regimen. The recommended regimen is $320 \mathrm{mg} \mathrm{m}^{-2}$ administered as a $20 \mathrm{~min}$ infusion once every 3 weeks. Myelosuppression, particularly neutropenia, is the dose-limiting toxicity for vinflunine and the severity of haematological toxicity is related to drug exposure $[5,6]$. The most frequent (incidence $>20 \%$ ) treatment related non-haematological adverse events in patients with advanced TCCU who received vinflunine were gastrointestinal symptoms (e.g. constipation, nausea, vomiting, stomatitis and abdominal pain), asthenia/fatigue, anorexia, alopecia, injection-site reactions and weight loss [7]. In general, all adverse events with vinflunine were non-cumulative and medically manageable. Currently, this drug is undergoing phase III clinical development in advanced breast cancer. The pharmacokinetics (PK) of VFL are linear over the dose range from 30 to $400 \mathrm{mg} \mathrm{m}^{-2}$ [8]. Following i.v. administration, VFL is eliminated according to a multiexponential decay with a sharp decrease in blood concentrations during the first hour post-infusion then by a slower decrease thereafter, the terminal half-life of VFL being close to $40 \mathrm{~h}$ [8]. VFL is characterized by a high total blood clearance $\left(>40 \mathrm{I} \mathrm{h}^{-1}\right)$ and a large volume of distribution (2422 I) suggesting that the drug is extensively distributed into tissues. VFL is moderately bound to plasma proteins (40-78\%), with a negligible binding to $\alpha_{1}$-glycoprotein and platelets [9]. As for the other vinca alkaloids, VFL exhibits an important metabolism. It is metabolized by liver cytochromes (mainly CYP3A4 isoenzymes) into several inactive metabolites and by multiple esterases into 4-Odeacetylvinflunine (DVFL), which is the predominant and only active metabolite of vinflunine [10]. In two large studied cohorts of patients with solid tumours (5000 patients each), the prevalence of a glomerular filtration rate (GFR) below $90 \mathrm{ml} \mathrm{min}^{-1}$ was calculated as high as $50 \%$ and the incidence of a GFR below $60 \mathrm{ml} \mathrm{min}^{-1}$, corresponding to stage 3 or more kidney disease was 12\% [11, 12]. Cancer patients have compromised renal function because of the underlying disease or for other causes such as ageing, high blood pressure, diabetes, infectious and autoimmune disease, or drug-related toxicity. It is now well established that renal dysfunction can affect not only the PK of drugs that are significantly eliminated by renal pathway but also the PK of some drugs that are predomi- nantly eliminated by a non-renal route. The mechanistic basis for the effect of renal impairment on non-renally eliminated drugs is not well understood, but may be linked to the inhibitory effects of uraemic toxins on drug metabolism enzymes or transporters [13].

Renal dysfunction may therefore induce important variations of drug exposure, even for some drugs that are predominantly non-renally eliminated, which may result in the alteration of the safety and/or efficacy profile. For vinorelbine, a structurally analogue to vinflunine, a weak correlation was evidenced between drug clearance and creatinine clearance $\left(\mathrm{CL}_{\mathrm{cr}}\right)$ despite the limited role of renal excretion $(<20 \%)$ to the total drug elimination [14].

Because the impact of renal impairment is minor, no dose adjustment is recommended for Vinorelbine. For vinflunine, a phase I mass balance study indicates that this drug is predominantly excreted via the biliary route however the renal excretion is not negligible and superior to that observed with vinorelbine: two-thirds of the recovered VFL dose is excreted into the faeces while one-third is excreted into the urine [9]. Consequently, it could be questioned whether a compromised renal function would affect the PK of VFL, possibly resulting in drug overexposure and increased toxicity.

In order to address the above issue, the present study was designed to evaluate the effect of renal dysfunction on the pharmacokinetics and safety of VFL and to propose a dose adjustment if needed.

\section{Methods}

This was an open-label dose escalation study of i.v. VFL in patients with renal impairment conducted in five phase I French centres. The study protocol and its amendments were submitted and approved by an Ethics Committee (Comité Consultatif de Protection des Personnes dans la Recherche Biomédicale de Bourgogne, France) and French Health Authorities. None of the amendments modified the study design. The trial was designed according to the current Declaration of Helsinki [15] and conducted in accordance with Good Clinical Practice. Written informed consent was obtained from each participating patient before study entry.

\section{Patients selection}

Patients were eligible for the trial if they were $\geq 18$ years and had a histologically proven metastatic solid tumour for which effective and standard therapy was not currently available. Two groups of renally impaired patients were selected based on the values of $\mathrm{CL}_{c r}$ as a measure of GFR. The $\mathrm{CL}_{c r}$ values were calculated at baseline using the Cockcroft \& Gault formula [16] and serum creatinine values were assayed by a unique laboratory. This centralized determination enabled limited experimental variability. 
Patients with $\mathrm{CL}_{\mathrm{cr}} \geq 40$ and $\leq 60 \mathrm{ml} \mathrm{min}{ }^{-1}$ were defined as the moderate renally impaired group (group 1) and patients with a $\mathrm{CL}_{\mathrm{cr}} \geq 20$ and $<40 \mathrm{ml} \mathrm{min}{ }^{-1}$ were defined as the severe renally impaired group (group 2). Both groups of patients were recruited simultaneously. At least 12 patients per group were planned to be included. Other requirements included predicted life expectancy $\geq 3$ months; a Eastern Cooperative Oncology Group (ECOG) performance status $(P S) \leq 2$, no severe or uncontrolled medical conditions, adequate haematologic count, no severe liver impairment according to international standard values and electrocardiogram (ECG) without any clinically significant abnormality. Radiotherapy may have been given provided that 3 weeks had elapsed prior to study entry. Patients must have recovered from adverse events due to agents administered $>4$ weeks earlier or $\geq 6$ weeks for nitrourea or mitomycine $C$.

Main non-inclusion criteria were concurrent treatment with any other anti-cancer therapy, participation into a clinical study with an investigational drug within 28 days before study entry, history of significant neurological or psychiatric disorders, previous treatment with VFL or another vinca alkaloid; prior extensive radiotherapy, prior known hypersensitivity to the study drug or drugs with similar chemical structures, an uncontrolled medical disorder, pre-existing peripheral neuropathy, uncontrolled hypercalcaemia, pregnancy, lactation or refusal to use effective contraception.

\section{Study drug administration and dose adjustement}

The starting dose of VFL was given according to the degree of renal impairment. A patient with $\mathrm{CL}_{c r} \geq 40$ and $\leq$ $60 \mathrm{ml} \mathrm{min}^{-1}$ received $280 \mathrm{mg} \mathrm{m}^{-2}$ of VFL while a patient with $\mathrm{CL}_{\mathrm{cr}} \geq 20$ and $<40 \mathrm{ml} \mathrm{min}^{-1}$ received $250 \mathrm{mg} \mathrm{m}^{-2}$. These anticipated dose reductions, respectively $13 \%$ and $22 \%$ lower than the recommended dose (i.e. $320 \mathrm{mg} \mathrm{m}^{-2}$ ) in patients with normal renal function, were consistent with the magnitude of the recovered dose in urine (i.e. $30 \%)$ after radiolabelled drug administration. The drug was administered intravenously diluted in a $100 \mathrm{ml}$ of normal saline over 20 min every 3 weeks, a 3 week period representing 1 cycle.
After the first administration, both pharmacokinetic and safety criteria (see Table 1) were used to adjust the second VFL dose so as to reach blood exposures in the range of those observed at the recommended dose of $320 \mathrm{mg} \mathrm{m}^{-2}$ in clinical trials to patients with $\mathrm{CL}_{\mathrm{cr}}>$ $60 \mathrm{ml} \mathrm{min}^{-1}$. The pharmacokinetic criterion was calculated from an historical control cohort of 118 patients with $\mathrm{CL}_{\mathrm{cr}}$ > $60 \mathrm{ml} \mathrm{min}{ }^{-1}$, these patients having been included in previous VFL single agent phase I/II studies [8, 17-20]. It was calculated as the dose normalized AUC (AUC divided by dose) corresponding to the upper bound of the $95 \%$ parametric confidence interval $(\mathrm{Cl})$ from the control population. This upper bound was estimated to be 65 meaning that most of the control patients with $\mathrm{CL}_{\mathrm{cr}}>60 \mathrm{ml} \mathrm{min}{ }^{-1}$ (97.5\%) had a lower value.

This strategy was performed to enable dose maintenance or dose escalation within the same patient in the case of good tolerance observed during the first cycle, therefore maximizing the probability of administering active doses to patients in cycle 2 while limiting the risk of drug overexposure.

According to the rules depicted in Table 1, in the absence of serious toxicity observed during cycle 1, VFL dose at cycle 2 could be either maintained at 280 or increased to $320 \mathrm{mg} \mathrm{m}^{-2}$ in patients of group 1 while the dose could be either maintained at $250 \mathrm{mg} \mathrm{m}^{-2}$ or increased to $320 \mathrm{mg} \mathrm{m}^{-2}$ in patients in group 2. Once tolerance was judged acceptable for cycle 1, dose maintenance or dose increase depended on the PK criteria. When the $\operatorname{A\cup C}(0, \infty) /$ Dose was below 65 which implied that the individual PK characteristic was within the $95 \%$ distribution to that observed in the control population, thus highly suggesting no or clinically irrelevant impact of the renal impairment on VFL clearance, the dose could be escalated to the recommended dose. For groups 1 and 2, the dose increase (respectively $13 \%$ and $28 \%$ ) was judged as reasonable for the individual to benefit from a therapeutic exposure.

When the $\operatorname{AUC}(0, \infty) /$ dose was higher than 65 , meaning that the individual exposure was within the top $5 \%$ distribution to that observed in the control population, the dose was maintained in the second cycle as the tolerance was good during the first cycle.

\section{Table 1}

Rules for dose adjustment in cycle 2

\begin{tabular}{|c|c|c|}
\hline \multirow{5}{*}{$\begin{array}{l}\text { AUC }(0, \infty) / \text { dose }\left(\mathrm{mg} \mathrm{m}^{-2}\right) \\
\text { of VFL in cycle } 1\end{array}$} & \multicolumn{2}{|c|}{ Dose of VFL in cycle 2} \\
\hline & Group 1 & Group 2 \\
\hline & Moderate renal impairment & Severe renal impairment \\
\hline & $\left(\mathrm{CL}_{\mathrm{cr}}\right.$ from $40 \mathrm{ml} \mathrm{min}^{-1}$ to $60 \mathrm{ml} \mathrm{min}^{-1}$ ) & $\left(\mathrm{CL}_{\mathrm{cr}}\right.$ from $20 \mathrm{ml} \mathrm{min}^{-1}$ to $\left.40 \mathrm{ml} \mathrm{min}^{-1}\right)$ \\
\hline & Starting dose: $280 \mathrm{mg} \mathrm{m}^{-2}$ & Starting dose: $250 \mathrm{mg} \mathrm{m}^{-2}$ \\
\hline$<65$ & $320 \mathrm{mg} \mathrm{m}^{-2}$ or $250 \mathrm{mg} \mathrm{m}^{-2}$ in case of poor tolerance & $320 \mathrm{mg} \mathrm{m}^{-2}$ or $210 \mathrm{mg} \mathrm{m}^{-2}$ in case of poor tolerance \\
\hline$\geq 65$ & $280 \mathrm{mg} \mathrm{m}^{-2}$ or $250 \mathrm{mg} \mathrm{m}^{-2}$ in case of poor tolerance & $250 \mathrm{mg} \mathrm{m}^{-2}$ or $210 \mathrm{mg} \mathrm{m}^{-2}$ in case of poor tolerance \\
\hline
\end{tabular}


In the case of grade IV neutropenia $\geq 7$ days, febrile neutropenia, constipation grade 3 , mucositis grade $2>5$ days or any grade $\geq 3$ toxicity (except untreated nausea or vomiting) observed in cycle 1, the dose of the second cycle was reduced as depicted in Table 1, independently of the blood exposure obtained on the first cycle. No dose re-escalation was allowed after a dose reduction. If a second episode of poor safety was observed or the grade $\geq$ 3 of toxicity was not resolved to grade $\leq 1$ for a maximum of 2 weeks, the patient was withdrawn from the study.

Cohorts of 20 patients were planned in each group of renal impairment. Patients received study treatment until disease progression, evidence of unacceptable toxicity or patient's request to discontinue the therapy.

\section{Treatment evaluation}

Safety was assessed by physical examination (including vital signs, weight, ECG, regular reporting of adverse events graded according to the NCI-CTC - version 2.0) and laboratory tests (complete blood cell counts, differential and platelets count, serum chemistry including liver function tests and $\mathrm{CL}_{c r}$, glucose, sodium, potassium, total protein), at baseline, and before each study drug administration in the following cycles. Haematology was performed every 2 days in the case of an absolute neutrophil count $<1.0 \times 10^{9} \mathrm{I}^{-1}$ until recovery. Patients who received at least one study treatment administration were considered evaluable for safety analysis unless they were lost to follow-up immediately after the start of treatment.

Efficacy was assessed by using RECIST (version 1.0) [21], the primary efficacy variable being the clinical response. Lesions were categorized into measurable or nonmeasurable lesions, target or non-target lesions. Tumour assessments were performed at baseline, the end of cycle 2 and then every two cycles.

\section{Clinical statistics}

All patients were included in the intent to treat analysis. Safety analysis was done on all treated patients. The analysis was performed for each dose level and for the whole treated population. Categorical variables were summarized with frequency and percentage, and continuous variables were summarized with frequency, median, range and, if relevant, mean and SD.

\section{Pharmacokinetics}

Blood sampling for pharmacokinetic assessment was carried out on day 1 of cycle 1 just before the start of administration and then $10 \mathrm{~min}$ (mid-infusion), $20 \mathrm{~min}$ (end of infusion), $40 \mathrm{~min}, 1 \mathrm{~h}, 1.5 \mathrm{~h}, 2 \mathrm{~h}, 4 \mathrm{~h}, 8 \mathrm{~h}, 12 \mathrm{~h}, 24 \mathrm{~h}$, $48 \mathrm{~h}, 96 \mathrm{~h}$ and $168 \mathrm{~h}$ after the start of infusion. The same sampling scheme was performed after the administration of the second cycle. The PK of VFL were evaluated by measuring its concentrations and those of its only active metabolite DVFL in whole blood using a fully validated LC/MS-MS method with a lower limit of quantification of $0.25 \mathrm{ng} \mathrm{ml}^{-1}$ [22].
For VFL, the calculated pharmacokinetic parameters were the peak concentration $\left(C_{\max }\right)$, the area under the blood concentration vs. time curve extrapolated from zero to infinity $(\operatorname{A\cup C}(0, \infty))$, the total blood clearance $\left(\mathrm{CL}_{\text {tot }}\right)$, the terminal volume of distribution $\left(V_{\mathrm{d}, z}\right)$ and the terminal blood half-life $\left(t_{1 / 2, z}\right)$. For DVFL, the peak concentration $\left(C_{\max }\right)$, the area under the blood concentration vs. time curve from zero to the last quantifiable concentration $\left(A \cup C\left(0, t_{\text {last }}\right)\right)$ and the metabolic ratio calculated as the ratio of DVFL $A \cup C\left(0, t_{\text {last }}\right): \operatorname{VFL~} \operatorname{AUC}\left(0, t_{\text {last }}\right)$ were also calculated. All PK parameters were derived from a modelindependent approach using Kinetica (v. 4.4) software (Thermo Electron Corp., USA). The PK parameters of VFL and DVFL from each renally impaired group (test groups) were compared with those obtained from historical control groups representing patients with normal renal function $\left(\mathrm{CL}_{\mathrm{cr}}>60 \mathrm{ml} \mathrm{min}^{-1}\right)$. For $\mathrm{VFL}$, the control group included a total of 118 patients from both single agent phase I and phase II clinical trials and for DVFL, the control group included a total of 44 patients from exclusively single agent phase I clinical trials. The potential impact of renal impairment was evaluated by calculating the $90 \% \mathrm{Cl}$ for the test (each group separately) : control ratio of geometric means of total blood clearance for VFL and of the metabolic ratio for DVFL. As defined in the regulatory guidelines [23], a lack of impact was concluded if the calculated $90 \% \mathrm{Cl}$ was included within the acceptance range of $0.80-1.25$. A regression model (i.e. linear model) based on data of all groups (tests and control) was performed to characterize adequately the relationship between drug clearance and renal function. All statistics were done using the SAS software (version 8.2. Cary, USA).

\section{Results}

\section{Patients' characteristics}

Patients' characteristics are shown in Table 2. Thirty-three patients were treated between August 2005 and April 2010 in five centres, 13 in group 1 (moderate renal impairment) and 20 in group 2. (severe renal impairment).

The median $\mathrm{CL}_{\mathrm{cr}}$ value was $45.3 \mathrm{ml} \mathrm{min}{ }^{-1}(40.8-51.1)$ in group 1 and $33.8 \mathrm{ml} \mathrm{min}^{-1}$ (20.7-39.9) in group 2 .

The patients had a large variety of tumour types. The most frequent histology was adenocarcinoma (51.5\%). All treated patients presented with metastatic disease.

For the control group, 118 patients coming from prior phase I/II studies were selected based on a GFR > $60 \mathrm{ml} \mathrm{min}^{-1}$. The mean value of GFR was $90.0 \mathrm{ml} \mathrm{min}^{-1}$ and ranged between 60.7 to $162 \mathrm{ml} \mathrm{min}^{-1}$. Most of the control group patients were male $(76 \%)$ and their mean age was 56 years (range: $25-78$ ).

\section{Treatment delivery}

A total of 100 cycles were delivered among the 33 treated patients. The median number of cycles was 2 with a range 


\section{Table 2}

Patients, baseline demographics and disease characteristics

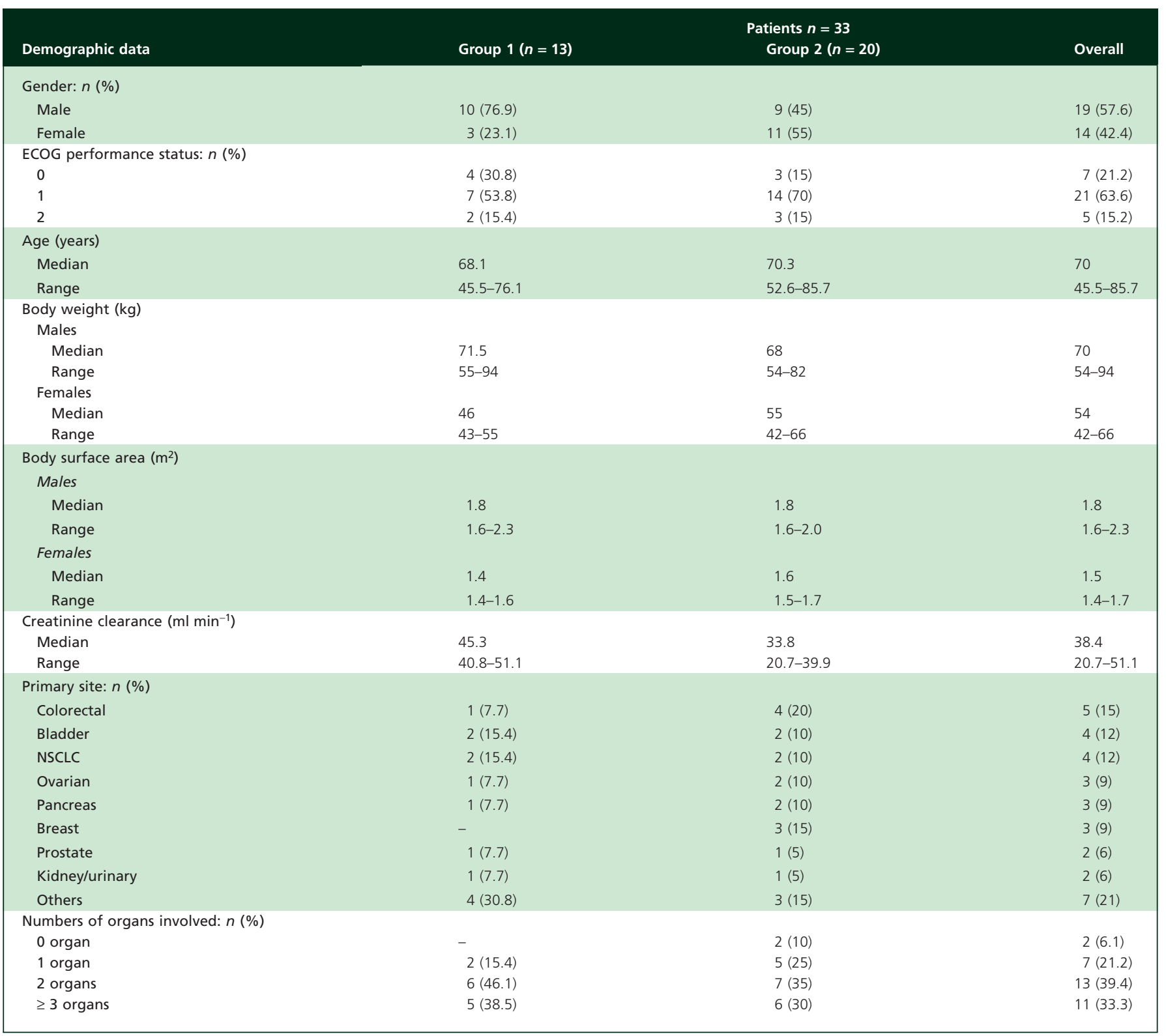

Others: primary site included oesophageal cancer (1), endometrium cancer (1), hepatocarcinoma (1), small cell lung cancer (1), soft tissue sarcoma (1), Vater's ampulla (1), unknown primary (1).

of 1 to 12 cycles. Twelve patients (36.4\%) received at least 3 cycles. The median relative dose intensity of i.v. VFL was $95.6 \%(80.3-105.7)$ in group 1 and $94.5 \%(74.3-109.9)$ in group 2. As per protocol, a total of 16 patients $(48.4 \%)$ had a VFL dose increase (seven patients in group 1 and nine patients in group 2) between cycle 1 and cycle 2 .

In the first group ( $n=13)$ after the first administration of $280 \mathrm{mg} \mathrm{m}^{-2}$ of $\mathrm{VFL}$, two patients were withdrawn after cycle 1 due to disease progression. In the same group, four patients had dose reduction for the second cycle due to grade 3 dehydration and asthenia (two patients), grade 3 constipation (one patient) and grade 4 neutropenia and grade 3 fatigue (one patient). Two additional dose reductions to $280 \mathrm{mg} \mathrm{m}^{-2}$ for patients who received $320 \mathrm{mg} \mathrm{m}^{-2}$ on cycle 2 were applied in this group for cycle 3 due to grade 3 constipation.

In the second group $(n=20)$, after the first administration of $250 \mathrm{mg} \mathrm{m}^{-2}$ of VFL, three patients were withdrawn after cycle 1 due to either safety reasons, patient decision or protocol deviation. In the same group, five patients had a dose reduction for the second cycle due to grade 3 constipation, grade 3 asthenia, grade 3 neutropenic infection, 


\section{Table 3A}

Evolution of vinflunine dose schedule during the study in patients in group 1

\begin{tabular}{|c|c|c|}
\hline $\begin{array}{l}\text { Evolution of vinflunine dose schedule during study } \\
\text { Group } 1 \text { starting dose at cycle } 1=280 \mathrm{mg} \mathrm{m}^{-2}\end{array}$ & $n$ & $\%$ \\
\hline Decrease to $210 \mathrm{mg} \mathrm{m}^{-2}$ at cycle $2-$ up to cycle 3 & 1 & 7.7 \\
\hline Decrease to $250 \mathrm{mg} \mathrm{m}^{-2}$ at cycle 2 - up to cycle 2 & 2 & 15.4 \\
\hline Decrease to $250 \mathrm{mg} \mathrm{m}^{-2}$ at cycle 2 - up to cycle 4 & 1 & 7.7 \\
\hline Increase to $320 \mathrm{mg} \mathrm{m}^{-2}$ at cycle $2-$ up to cycle 2 & 3 & 23.1 \\
\hline Increase to $320 \mathrm{mg} \mathrm{m}^{-2}$ at cycle 2 - up to cycle 3 & 1 & 7.7 \\
\hline Increase to $320 \mathrm{mg} \mathrm{m}^{-2}$ at cycle 2 - up to cycle 6 & 1 & 7.7 \\
\hline $\begin{array}{l}\text { Increase to } 320 \mathrm{mg} \mathrm{m}^{-2} \text { at cycle } 2 \text {, decrease to } \\
280 \mathrm{mg} \mathrm{m}^{-2} \text { at cycle } 3 \text { - up to cycle } 4\end{array}$ & 1 & 7.7 \\
\hline $\begin{array}{l}\text { Increase to } 320 \mathrm{mg} \mathrm{m}^{-2} \text { at cycle } 2 \text {, decrease to } \\
280 \mathrm{mg} \mathrm{m}^{-2} \text { at cycle } 3-\text { up to cycle } 7\end{array}$ & 1 & 7.7 \\
\hline Not treated after cycle 1 & 2 & 15.4 \\
\hline Number of patients & 13 & 100.0 \\
\hline
\end{tabular}

\section{Table 3B}

Evolution of vinflunine dose schedule during the study in oatients in group 2

\begin{tabular}{|c|c|c|}
\hline $\begin{array}{l}\text { Evolution of vinflunine dose schedule during study } \\
\text { Group } 2 \text { starting dose at cycle } 1=250 \mathrm{mg} \mathrm{m}^{-2}\end{array}$ & $n$ & $\%$ \\
\hline Decrease to $210 \mathrm{mg} \mathrm{m}^{-2}$ at cycle 2 - up to cycle 2 & 4 & 20.0 \\
\hline Decrease to $210 \mathrm{mg} \mathrm{m}^{-2}$ at cycle $2-$ up to cycle 4 & 1 & 5.0 \\
\hline Increase to $280 \mathrm{mg} \mathrm{m}^{-2}$ at cycle $2-$ up to cycle 3 & 1 & 5.0 \\
\hline Increase to $320 \mathrm{mg} \mathrm{m}^{-2}$ at cycle $2-$ up to cycle 12 & 1 & 5.0 \\
\hline Increase to $320 \mathrm{mg} \mathrm{m}^{-2}$ at cycle 2 - up to cycle 2 & 5 & 25.0 \\
\hline $\begin{array}{l}\text { Increase to } 320 \mathrm{mg} \mathrm{m}^{-2} \text { at cycle } 2 \text {, decrease to } \\
250 \mathrm{mg} / \mathrm{m}^{-2} \text { at cycle } 3 \text { - up to cycle } 11\end{array}$ & 1 & 5.0 \\
\hline $\begin{array}{l}\text { Increase to } 320 \mathrm{mg} \mathrm{m}^{-2} \text { at cycle } 2 \text {, decrease to } \\
\qquad 280 \mathrm{mg} / \mathrm{m}^{-2} \text { at cycle } 3-\text { up to cycle } 3\end{array}$ & 1 & 5.0 \\
\hline No change up to cycle 2 & 2 & 10.0 \\
\hline No change up to cycle 3 & 1 & 5.0 \\
\hline Not treated after cycle 1 & 3 & 15.0 \\
\hline Number of patients & 20 & 100.0 \\
\hline
\end{tabular}

grade 4 neutropenia and grade 3 arthralgia (one patient each). One additional dose reduction to $280 \mathrm{mg} \mathrm{m}^{-2}$ was applied for cycle 3 in one patient for whom VFL was administered at $320 \mathrm{mg} \mathrm{m}^{-2}$ at cycle 2 due to grade 2 jaw pain. In three patients, no dose modification was applied.

Tables $3 \mathrm{~A}$ and $\mathrm{B}$ display an overview of doses changes per group.

\section{Safety}

All patients in each group were evaluable for safety at cycle 1 . At cycle 2, 10 and 16 patients were evaluable in group 1 and 2, respectively. No toxic death occurred during the study and no unexpected adverse events were recorded.

The worst grade of haematological toxicities by patient (33 patients, 100 cycles) are depicted in Table 4. Grade 3 febrile neutropenia was reported in two patients from group 1 after cycle $1\left(280 \mathrm{mg} \mathrm{m}^{-2}\right)$ and $3\left(210 \mathrm{mg} \mathrm{m}^{-2}\right)$, respectively. Throughout the study, treatment related non-haematological adverse events were as follows. Asthenia was the most frequent adverse event (AE) whatever the group, concerning nine out of 13 patients in group 1, and 14 out of 20 patients in group 2. Gastrointestinal disorders were also frequent. The main gastrointestinal adverse event was constipation reported in eight and 14 patients in groups 1 and 2, respectively. Although no grade 4 constipation was recorded during the study, eight patients (three patients in group 1 and five patients in group 2) experienced eight episodes of grade 3 constipation. Anorexia was frequently reported in $61 \%$ of the group 1 patients (one grade 3 and two grade 4 ) and in $40 \%$ of the the group 2 patients (one grade 4). Nausea and vomiting were also reported (group 1: eight patients, no grade 3/4; group 2: seven patients, no grade 3/4). Eight patients had stomatitis but none had a grade 3 or 4 . Six patients experienced diarrhoea without any grade 3 or 4 . One patient in group 2 experienced one episode of grade 4 dysphagia. The major pain observed during the study was abdominal pain: $31 \%$ in group 1 and $60 \%$ in group 2 experienced this AE with one grade 3 in each group and one grade 4 in group 2). Myalgia was reported in $23 \%$ of patients in group 1 (one grade 3 ) and in $30 \%$ of patients in group 2. Arthralgia was only reported in $15 \%$ of patients in the group 1 and $5 \%$ of the patients in the group 2 with one grade 3 ). Cardiovascular AEs were infrequent, one patient presented with one episode of grade 1 tachycardia and one patient one episode of grade 4 myocardial infarction. Grade 3 dehydration was observed in two patients out of 13 in group 1 and in one patient in group 2 .

\section{Efficacy}

Efficacy was assessed by using RECIST (version 1.0). Five patients were unevaluable for response, one in the moderate renal impairment group and four in the severe group. No partial response was observed. A total of 11 disease stabilizations (at least 2 cycles of treatment) was achieved (33.3\%). The median duration of stabilization and the median progression-free survival were 5.3 months $(95 \% \mathrm{Cl} 2.6,6.6)$ and 1.7 months $(95 \% \mathrm{Cl} 1.4,3.1)$, respectively. With a median follow up of 39 months, the median overall survival was 6.1 months $(95 \% \mathrm{Cl} 3.7,9.4)$.

\section{Pharmacokinetics}

For the first cycle, 13 and 16 patients provided full and interpretable PK results in the moderate $\left(280 \mathrm{mg} \mathrm{m}^{-2}\right)$ and severe $\left(250 \mathrm{mg} \mathrm{m}^{-2}\right)$ renally impaired group, respectively. For the second cycle, interpretable PK results were available in 10 patients for each group. The main PK parameters calculated for the first cycle stratified by group are reported in Table 5.

For VFL, $C_{\max }$ and $\operatorname{AUC}(0, \infty)$ showed similar mean and range values between moderate and severe renally 


\section{Table 4}

Haematological toxicities (worst grade on study by patient)

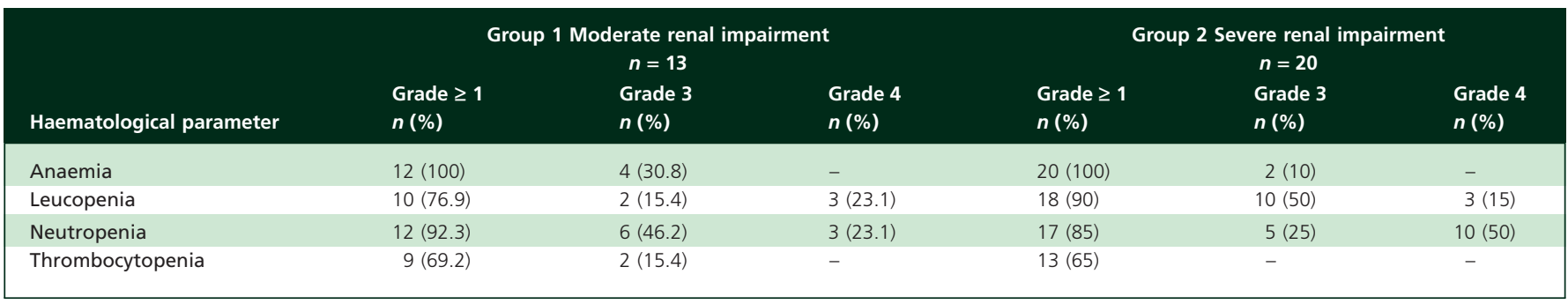

impaired groups whereas both the total blood clearance and the terminal volume of distribution decreased with the severity of renal impairment. As a consequence of a similar decrease for both PK parameters $\left(\mathrm{CL}_{\text {tot }}\right.$ and $\left.V_{\mathrm{d}, \mathrm{z}}\right)$, the mean terminal half-life was comparable between the two groups.

For DVFL, values of $C_{\max }, \mathrm{AUC}\left(0, t_{\text {last }}\right)$ and metabolic ratio were in the same range for moderate and severe renally impaired groups. Although based on a small number of patients per group and dose, the same trends were observed for VFL and DVFL PK parameters for cycle 2 (data not shown).

Owing to the limited number of patients with evaluable PK data at cycle $2(n<12)$, statistical analyses were performed for the PK parameters of cycle 1 only.

For VFL, a $12 \%$ and $28 \%$ decrease in VFL clearance mean values was estimated respectively for the moderate and the severe renally impaired group as compared with the control patients with $\mathrm{CL}_{\mathrm{cr}}>60 \mathrm{ml} \mathrm{min}{ }^{-1}$ (Table 6).

When each renally impaired group was compared with the control group, Cls were calculated outside the acceptance range of $0.80-1.25$ illustrating a non-equivalent clearance between each test group and the control group. The decrease in total blood clearance according to the severity of renal dysfunction was further confirmed by investigating the relationship between the VFL blood clearance obtained in cycle 1 and 2 and the $\mathrm{CL}_{c r}$ normalized to a body surface area of $1.73 \mathrm{~m}^{2}$ (Figure 1). No significant correlation was observed in patients with a $\mathrm{CL}_{c r}$ higher than $60 \mathrm{ml} \mathrm{min}-11.73 \mathrm{~m}^{-2}$ whereas a highly significant correlation ( $r=0.40, P<0.01$, Pearson's test) was demonstrated in patients with a $\mathrm{CL}_{c r}$ lower than $60 \mathrm{ml} \mathrm{min}^{-1} 1.73 \mathrm{~m}^{2}$. In renally impaired patients, the regression equation was VFL $\mathrm{CL}_{\text {tot }}\left(\mathrm{I} \mathrm{h}^{-1} \mathrm{~m}^{-2}\right)=0.217 \times \mathrm{CL}_{\mathrm{cr}}$ $\left(\mathrm{ml} \mathrm{min} \mathrm{m}^{-1} 1.73 \mathrm{~m}^{-2}\right)+10.1$. Of note, it can be observed on Figure 1 that the clearance data distribution between cycle 1 and cycle 2 were similar. Individual values of VFL $\operatorname{A\cup C}(0, \infty)$ obtained in cycle 1 are depicted in Figure 2. While the total blood clearance of VFL was demonstrated to be significantly lower in each renally impaired group compared with the control group, the observed drug exposure showed comparable distribution between groups, with mean \pm SD values of $14212 \pm 3483,14422 \pm$
4358 and $15521 \pm 3723 \mathrm{ng} \mathrm{ml}^{-1} \mathrm{~h}$ for the control, moderate and severe renally impaired groups, respectively.

For DVFL, a $19 \%$ and $2 \%$ increase in the metabolic ratio were estimated respectively for the moderate and the severe renally impaired groups as compared with the control group (Table 6). A lack of equivalence was observed between moderate and control groups whereas equivalence was shown between severe and control groups. This discrepancy could be explained by two patients from the moderate renally impaired group presenting higher metabolic ratios than the normal range values.

The mean DVFL exposure $\left(A \cup C\left(0, t_{\text {last }}\right)\right)$ was slightly higher in each renally impaired group compared with the control group (Table 5). The difference was borderline statistically significant $(P<0.045, t$-test) between the moderate and control groups and there was no statistically significant difference between the severe and control groups $(P<0.20, t$-test). Should an impact of renal impairment on DVFL elimination occur, the DVFL exposure in the severe group would have been significantly higher than that observed in the control and moderate groups. In addition, the individual values of DVFL exposure illustrated comparable distributions among groups (Figure 2). It was therefore considered that DVFL exposure in the renal dysfunction groups was essentially similar to that observed in the control group.

\section{Discussion}

The results of a recent study showed that the prevalence of renal insufficiency in cancer patents may be as high as $60 \%[11,12]$. Despite this relatively high frequency, the information concerning dosage adjustment in renally impaired patients is infrequently available. Phases II/III clinical trials supporting drug development are performed in patients with normal organ function and poor information exists on the pharmacokinetics and/or pharmacodynamics of drugs in patients with organ dysfunction, and especially in renally impaired cancer patients. This practice poses a significant challenge to the treating physicians on how to select appropriate dosing. In a conservative 
approach, oncologists withhold systemic chemotherapy for patients with severe renal dysfunction. This situation does not benefit patients with organ dysfunction who may have no available therapy. In order to address this issue, specific phase I trials are encouraged by regulatory agencies who recommend study designs evaluating the PK of drugs over a full range of renal function, from normal GFR $\left(>80 \mathrm{ml} \mathrm{min}^{-1}\right)$ to severely impaired GFR $\left(<30 \mathrm{ml} \mathrm{min}^{-1}\right)$ [24]. It is well acknowledged that such a full range design is difficult to conduct in cancer patients and that the recruitment could be long. In the present case, an original study design was carried out in renally impaired patients with the use of all pertinent PK data collected during the drug development prior to initiating the current study. Indeed, the clinical programme for VFL authorized the inclusion of

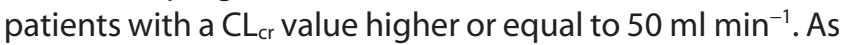
a consequence, $\mathrm{PK}$ data were available in the range of $\mathrm{CL}_{\mathrm{cr}}$ $>80 \mathrm{ml} \mathrm{min}^{-1}$ corresponding to normal renal function as well as in the range of $\mathrm{CL}_{\mathrm{cr}} \geq 50$ to $\leq 80 \mathrm{ml} \mathrm{min}^{-1}$ corresponding to mild impaired renal function. These background data demonstrated no PK difference between patients with GFR $>80 \mathrm{ml} \mathrm{min}^{-1}$ and patients with GFR ranging from 60 to $80 \mathrm{ml} \mathrm{min}^{-1}$. This prior information enabled us to define patients with a GFR $>60 \mathrm{ml} \mathrm{min}^{-1}$ as a control group, to use this historical data and to investigate two groups with impaired renal function with the same length interval: $40-60 \mathrm{ml} \mathrm{min}-1$ and 20 to $<40 \mathrm{ml} \mathrm{min}^{-1}$. This study design was successful to discriminate reliably a decreased clearance value of $12 \%$ in the first group and a more substantial decrease of $28 \%$ in the second group when compared with the control group. Based on a $90 \% \mathrm{Cl}$ approach, both reduced values were evidenced as nonequivalent compared with the control group, therefore justifying clinically the dose adjustments.

Although no reliable information was available in patients with moderate to severe renal dysfunction at the time of designing the current study protocol, the starting dose were reduced from $320 \mathrm{mg} \mathrm{m}^{-2}$ to $280 \mathrm{mg} \mathrm{m}^{-2}$ and $250 \mathrm{mg} \mathrm{m}^{-2}$ in patients in groups 1 and 2, respectively. These dose reductions are in close agreement with the magnitude of decrease in drug clearance. In both groups of renal dysfunction, VFL and DVFL exposure in the first cycle was found to be comparable with that expected in a population treated at the recommended dose of $320 \mathrm{mg} \mathrm{m}^{-2}$ and having a GFR $>60 \mathrm{ml} \mathrm{min}^{-1}$ (Figure 2). The homogeneous distribution of blood exposure to VFL and to its active metabolite across the different groups confirmed the validity of dose reduction in renally impaired patients.

In addition to the anticipated dose reductions for the first cycle, both pharmacokinetic and safety criteria were introduced for further dose modifications in the second cycle (Table 1), therefore limiting the risk of underexposure and maximizing the probability of administering active doses. On average, dose modifications (increase or decrease) following cycle 1 did not result in a significant 


\section{Table 6}

Bioequivalence analysis of vinflunine blood clearance and of 4-O-deacetyl vinflunine metabolic ratio

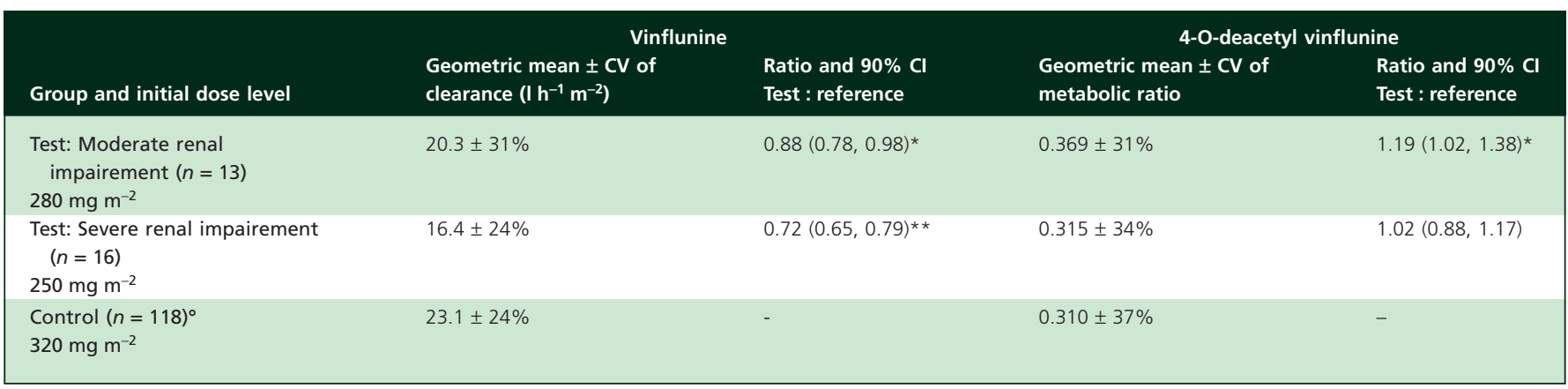

${ }^{* / * *}$ Not bioequivalent. ${ }^{\circ}$ Sample size for control of 4-O-deacetyl vinflunine metabolic ratio is 44 .

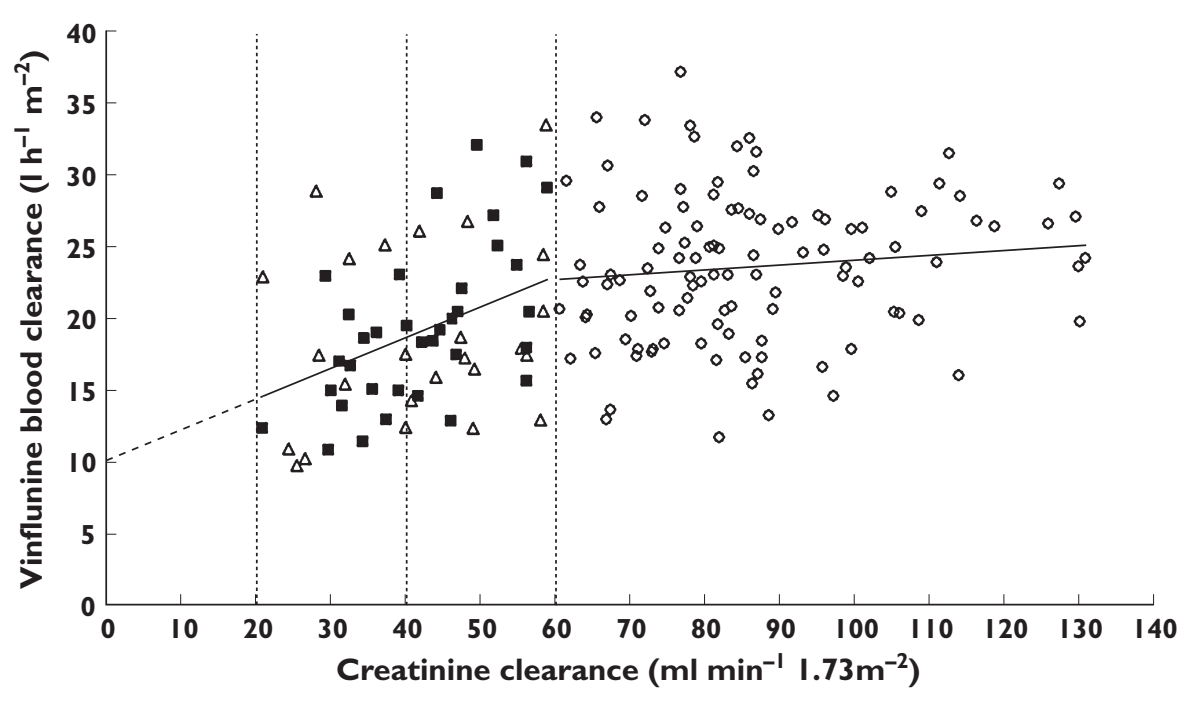

\section{Figure 1}

Relationship between individual vinflunine blood clearance and creatinine clearance. Open circles: data from control patients; Filled squares: data at cycle 1 from renally impaired patients; Open triangles: data at cycle 2 from renally impaired patients. A regression line was separately calculated between patients with renal impaired function (creatinine clearance $\leq 60 \mathrm{ml} \mathrm{min}^{-1} 1.73 \mathrm{~m}^{-2}, \mathrm{y}=0.217 \mathrm{x}+10.1$ ) vs. control patients (creatinine clearance $>60 \mathrm{ml} \mathrm{min}{ }^{-1}$ $\left.1.73 \mathrm{~m}^{-2}, y=0.0361 \mathrm{x}+20.5\right)$. The correlation coefficient was statistically significant $\left(r^{2}=0.16, P<0.01\right)$ for patients with impaired renal function whereas it was not statistically significant $\left(r^{2}=0.015, \mathrm{NS}\right)$ for control patients

change in the initial dosing (i.e. 280 and $250 \mathrm{mg} \mathrm{m}^{-2}$ in groups 1 and 2 , respectively) as illustrated by the median dose intensities $(96 \%$ and $95 \%$ in groups 1 and 2 , respectively).

Intravenous VFL administered to patients with renal impairment once every 3 weeks was found to be safe and well tolerated. Dose limiting toxicity (grade 3 febrile neutropenia) was experienced by two patients at $280 \mathrm{mg} \mathrm{m}^{-2}$ and $210 \mathrm{mg} \mathrm{m}^{-2}$ in group 1 . Among all the 33 patients, the most common non-haematological related adverse events were gastrointestinal events (66.6\%) and asthenia $(69.6 \%)$. These common side effects related to VFL were rarely severe. Safety data reported in the present phase I study were not unexpected and were consistent with the previously reported clinical experience with VFL in patients with GFR $>60 \mathrm{ml} \mathrm{min}{ }^{-1}$ [25-27].

One limitation of the present study was that no PK and safety data were obtained in patients with end-stage renal disease (ESRD) on dialysis. These types of patients may present with a GFR far below $20 \mathrm{ml} \mathrm{min}^{-1}$ and are rarely included in clinical trials. Extrapolating the regression equation of VFL $\mathrm{CL}_{\text {tot }}$ vs. $\mathrm{CL}_{\mathrm{cr}}$ in renally impaired patients [VFL $\mathrm{CL}_{\text {tot }}\left(\mathrm{I} \mathrm{h}^{-1} \mathrm{~m}^{-2}\right)=0.217 \times \mathrm{CL}_{\mathrm{cr}}\left(\mathrm{ml} \mathrm{min}^{-1} 1.73 \mathrm{~m}^{-2}\right)+$ 10.1] to the lower edge of $\mathrm{CL}_{c r}$ values may bring some pieces of information. Assuming that the linear regression still holds true for the lowest values of $\mathrm{CL}_{c r}$, a roughly $40-57 \%$ decreased $V F L C_{\text {tot }}$ is predicted when $\mathrm{CL}_{c r}$ ranges from below $20 \mathrm{ml} \mathrm{min}^{-1}$ to strictly no functional renal 

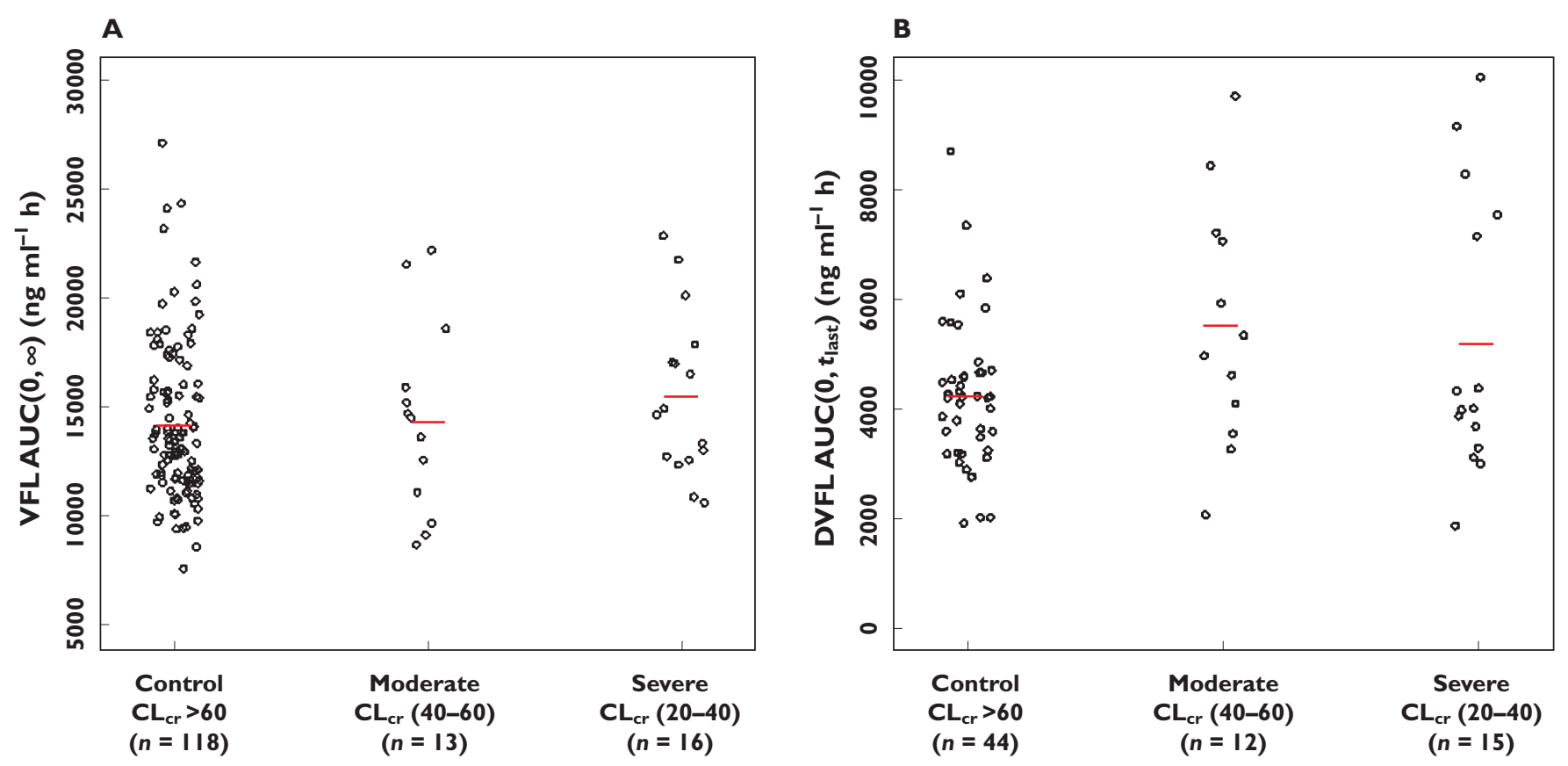

Figure 2

Individual vinflunine (A) and 4-O-deacetyl vinflunine (B) AUC between control and renally impaired groups. Red lines represents the mean values for each group

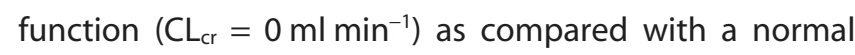
renal function $\left(\mathrm{CL}_{\mathrm{cr}} \geq 80 \mathrm{ml} \mathrm{min}{ }^{-1}\right)$. It can be therefore postulated that a $50 \%$ dose reduction in ESRD patients may be necessary to obtain equivalent drug exposure to that expected for patients with normal renal function. Another issue in ESRD is that the drug may be removed by dialysis and this must be taken into account for appropriate handling between chemotherapy timing and dialysis sessions. Concerning VFL, it can be hypothesized that its PK characteristics do not favour the removal of the drug by dialysis. A high volume of distribution, a long terminal half-life and the predominantly non-renal clearance exhibited by VFL likely limit the ability of the drug to be removed from the body by intermittent dialysis sessions. However, owing the absence of any data on the dialysis clearance of VFL, the administration of the drug could be done after dialysis sessions or on non-dilaysis days.

This study established that VFL should be administered once every 3 weeks to cancer patients with renal impairment at $280 \mathrm{mg} \mathrm{m}^{-2}$ when $\mathrm{CL}_{\mathrm{cr}}$ is included between 40 and $60 \mathrm{ml} \mathrm{min}^{-1}$ and at $250 \mathrm{mg} \mathrm{m}^{-2}$ when $\mathrm{CL}_{c r}$ is higher than $20 \mathrm{ml} \mathrm{min}^{-1}$ and strictly lower than $40 \mathrm{ml} \mathrm{min}^{-1}$. Moreover, even if the response rate was not a primary end point of the study it is noteworthy that in this heavily pretreated cancer patient population, 11 patients (33\%) achieved disease stabilization for at least 6 weeks.

These recommended doses in renally impaired patients enabled blood exposure to VFL and to its active metabolite to be similar to that achieved in patients with GFR $>60 \mathrm{ml} \mathrm{min}^{-1}$ treated at $320 \mathrm{mg} \mathrm{m}^{-2}$. Safety data at these doses in renally impaired patients demonstrated no unexpected toxicities and comparable tolerability profiles with patients with normal renal function.

\section{Competing Interests}

All authors have completed the Unified Competing Interest form at http://www.icmje.org/coi_disclosure.pdf (available on request from the corresponding author).

Dr N. Isambert, Dr J.P. Delord, Dr J.M. Tourani, Dr P. Fumoleau, $\operatorname{Dr}$ A. Ravaud and $\operatorname{Dr}$ T. Nguyen declare no support from any organization for the submitted work.

M.C. Pinel, L. Nguyen and A. Petain had support from Pierre Fabre Laboratories (their employer), the manufacturer of vinflunine. Pierre Fabre Laboratories supported preparation of this article.

The authors thank all the medical staff, and specially the nurses and laboratory teams for their involvement in patient care, data collection and PK samples management during the study.

\section{REFERENCES}

1 Hill BT, Fiebig HH, Waud WR, Poupon MF, Colpaert F, Kruczynski A. Superior in vivo experimental antitumour activity of vinflunine, relative to vinorelbine, in a panel of human tumour xenografts. Eur J Cancer 1999; 35: 512-20. 
2 Kruczynski A, Colpaert F, Tarayre JP, Mouillard P, Fahy J, Hill BT. Preclinical in vivo antitumor activity of vinflunine, a novel fluorinated Vinca alkaloid. Cancer Chemother Pharmacol 1998; 41: 437-47.

3 Kruczynski A, Poli M, Dossi R, Chazottes E, Berrichon G, Ricome C, Giavazzi R, Hill BT, Taraboletti G. Anti-angiogenic, vascular-disrupting and anti-metastatic activities of vinflunine, the latest vinca alkaloid in clinical development. Eur J Cancer 2006; 42: 2821-32.

4 Pourroy B, Honore S, Pasquier E, Bourgarel-Rey V, Kruczynski A, Briand C, Braguer D. Antiangiogenic concentrations of vinflunine increase the interphase microtubule dynamics and decrease the motility of endothelial cells. Cancer Res 2006; 66: 3256-63.

5 Bennouna J, Delord JP, Campone M. Vinflunine: a new microtubule inhibitor agent. Clin Cancer Res 2008; 14: 1625-32.

6 Friberg LE, Henningsson A, Maas H, Nguyen L, Karlsson MO. Model of chemotherapy-induced myelosuppression with parameter consistency across drugs. J Clin Oncol 2002; 20: 4713-21.

7 Schutz FAAB, Bellmunt J, Rosenberg JE, Choueiri TK. Vinflunine: drug safety evaluation of this novel synthetic vinca alkaloid. Expert Opin Drug Saf 2011; 10: 645-53.

8 Bennouna J, Fumoleau P, Armand JP, Raymond E, Campone M, Delgado FM, Puozzo C, Marty M. Phase I and pharmacokinetic study of the new vinca alkaloid vinflunine administered as a 10-min infusion every 3 weeks in patients with advanced solid tumours. Ann Oncol 2003; 14: 630-7.

9 Frampton JE, Moen MD. Vinflunine. Drugs 2010; 70: 1283-93.

10 Lobert S, Puozzo C. Pharmacokinetics, metabolites, and preclinical safety of vinflunine. Semin Oncol 2008; 35: S28-S33.

11 Launay-Vacher V, Oudard S, Janus N, Gligorov J, Pourrat X, Rixe O, Morere JF, Beuzeboc P, Deray G. Prevalence of renal insufficiency in cancer patients and implications for anticancer drug management: the renal insufficiency and anticancer medications (IRMA) study. Cancer 2007; 110: 1376-84.

12 Launay-Vacher V. Epidemiology of chronic kidney disease in cancer patients: lessons from the IRMA study group. Semin Nephrol 2010; 30: 548-56.

13 Lalonde RL, Wagner JA. Drug development perspective on pharmacokinetic studies of new drugs in patients with renal impairment. Clin Pharmacol Ther 2009; 86: 557-61.

14 Bonneterre J, Focan C, Mauriac L, Piccart M. Phase I and pharmacokinetic study of Navelbine oral (NVBo) in patients with advanced breast cancer. Proc. 11th Internat. Congress on Anti-Cancer Chemotherapy, 133-Abst.S02-04. 2001.

15 Rickman PP. Human experimentation. Code of ethics of the world medical association. Declaration of Helsinki. Br Med J 1964; 2: 177.

16 Cockcroft DW, Gault MH. Prediction of creatinine clearance from serum creatinine. Nephron. 1976; 16: 31-41.
17 Delord JP, Stupp R, Pinel MC. Phase I study of vinflunine given as a 10 minute intravenous (IV) infusion an a weekly schedule in patients (pts) with advanced solid tumours. Proc Am Soc Clin Oncol 2001; 20: 111 a.

18 Johnson P, Geldart T, Fumoleau P, Pinel MC, Nguyen L, Judson I. Phase I study of vinflunine administered as a 10-minute infusion on days 1 and 8 every 3 weeks. Invest New Drugs 2006; 24: 223-31.

19 Bennouna J, Breton JL, Tourani JM, Ottensmeier C, O'Brien M, Kosmidis P, Huat TE, Pinel MC, Colin C, Douillard JY. Vinflunine - an active chemotherapy for treatment of advanced non-small-cell lung cancer previously treated with a platinum-based regimen: results of a phase II study. Br J Cancer 2006; 94: 1383-8.

20 Souquet P-J, Krzakowski R, Ramlou R, Sun XS, Lopez-Vivanco G, Puozzo C, Pouget JC, Pinel MC, Rosell R. Phase I/II and pharmacokinetic study of intravenous vinflunine in combination with cisplatin for the treatment of chemonaive patients with advanced non small cell lung cancer. Clin Lung Cancer 2010; 11: 105-13.

21 Therasse P, Arbuck SG, Eisenhauer EA, Wanders J, Kaplan RS, Rubinstein L, Verweij J, Van Glabbeke M, van Oosterom AT, Christian MC, Gwyther SG. New guidelines to evaluate the response to treatment in solid tumors. European Organization for Research and Treatment of Cancer, National Cancer Institute of the United States, National Cancer Institute of Canada. J Natl Cancer Inst 2000; 92: 205-16.

22 Zorza G, Van Heugen JC, De Graeve J, Puozzo C. Development of a sensitive liquid chromatography method coupled with a tandem mass spectrometric detection for the clinical analysis of vinflunine and 4-O-deacetyl vinflunine in blood, urine and faeces. J Chromatogr B 2007; 853: 294-302.

23 CHMP. Guideline on the investigation of bioequivalence. EMEA 2010.

24 CHMP. Note for guidance on the evaluation of the pharmacokinetics of medicinal products in patients with impaired renal function. EMEA 2004.

25 Bellmunt J, Theodore C, Demkov T, Komyakov B, Sengelov L, Daugaard G, Caty A, Carles J, Jagiello-Gruszfeld A, Karyakin O, Delgado FM, Hurteloup P, Winquist E, Morsli N, Salhi Y, Culine $\mathrm{S}$, von der Maase $\mathrm{H}$. Phase III trial of vinflunine plus best supportive care compared with best supportive care alone after a platinum-containing regimen in patients with advanced transitional cell carcinoma of the urothelial tract. J Clin Oncol 2009; 27: 4454-61.

26 Fumoleau $\mathrm{P}$, Cortes-Funes $\mathrm{H}$, Taleb AB, Chan S, Campone $M$, Pouget JC, Tubiana-Hulin M, Slabber CF, Caroff-Paraïso I, Alberts AS, Ben Ayed F. Phase 2 study of single-agent IV vinflunine as third-line treatment of metastatic breast cancer after failure of anthracycline-/taxane-based chemotherapy. Am J Clin Oncol 2009; 32: 375-80.

27 Vaughn DJ, Srinivas S, Stadler WM, Pili R, Petrylak D, Sternberg CN, Smith DC, Ringuette S, de Wit E, Pautret V, George $C$. Vinflunine in platinum-pretreated patients with locally advanced or metastatic urothelial carcinoma: results of a large phase 2 study. Cancer 2009; 115: 4110-7. 